\title{
Evaluation of Organic Loading Rate and Chemical Oxygen Demand Removal: A Coupled Anaerobic- aerobic Treatment Approach for Molasses Distillery Stillage Treatment
}

\section{Getachew D. Gebreeyessus}

Africa Center of Excellence for Water Management, Addis Ababa University, P.O. Box 1176, Addis Ababa, Ethiopia. Department of UEM, Kotebe Metropolitan University, P.O. Box 31248, Addis Ababa, Ethiopia

\section{Andualem Mekonnen}

Center for Environmental Sciences, Addis Ababa University, P.O. Box 1176, Addis Ababa, Ethiopia

\section{Yonas Chebude}

Department of Chemistry, Addis Ababa University, P.O. Box 1176, Addis Ababa, Ethiopia

Asaithambi Perumal ( $\square$ drasaithambi2014@gmail.com)

Assistant Prof, JIT Jimma University https://orcid.org/0000-0002-0533-0178

\section{Esayas Alemayehu}

Department of Water Supply Environmental Engineering, Faculty of Civil and Environmental Engineering, Jimma Institute of Technology, Jimma University, P.O. Box 378, Jimma, Ethiopia

\section{Research}

Keywords: chemical oxygen demand, organic loading rate, scoria, stillage, sustainability

Posted Date: November 18th, 2020

DOI: https://doi.org/10.21203/rs.3.rs-107266/v1

License: (c) (i) This work is licensed under a Creative Commons Attribution 4.0 International License. Read Full License 


\section{Abstract}

The objective of the current study is to determine the optimum organic loading rate for a continuous anaerobic digestion (AD) of an ethanol distillery stillage with and without of feed pretreatment. The AD has been performed in scoria packed continuous reactors. The pretreatment of the molasses ethanol distillery stillage brought a significantly better chemical oxygen demand (COD) removal with an increased loading rate to $2000 \mathrm{mg} / \mathrm{L}-\mathrm{d}$, when compared with the raw. The results obtained also showed a complete removal of the BOD, which was realized after applying the coupling of $A D$ and aerobic treatments. During aerobic treatment, $68 \%$ of the organics were removed within eight hours of retention time. Despite the persistence of color, the removal of organics from integrating the wet air pretreatment, continuous $A D$ and aerobic remediations appear to be promising technique towards the sustainable management of stillage thereby meeting discharge limits.

\section{Introduction}

Alcohol use for potable, cleaning and fuel purposes is increasing with time and it is becoming a disintegrable phenomenon with population and economic growth as well as urbanization. The consumption of alcohol for both fuel and potable purpose is always increasing with time, even under the COVID-19 pandemic time ${ }^{1-5}$. However, the consumption of ethanol has got pros and cons regarding the water, energy and environment nexus worldwide ${ }^{6-8}$. This has led to the use of third generation biomass, distillery stillage, for energy generation, water reclamation and soil nutrient recovery thereby closing the gap in the economic cycle and ensure the sustainability of such sectors, especially in the developing countries ${ }^{9-11}$.

The application of ethanol stillage, a bottom product of alcohol distillation in a ratio of $12-18 \mathrm{l} / \mathrm{I}$ alcohol, for renewable energy and soil nutrition purpose is impeded by the recalcitrant nature of stillage due to the use of agri-chemicals and the byproducts formed from some reaction between the sugars and the amino acids. Furthermore, the chemical/biological oxygen demand (COD/BOD) falls above the discharge limits set by the regulatory authorities for ethanol industries to discharge their effluent to nearby environmental media ${ }^{12-14}$. Various stakeholders revealed their concern in minimizing the environmental footprint of ethanol industries, while at the same time improving the energy self-sufficiency through recovery of byproducts thereby ensuring the sustainability. Among the participants on the issues of ethanol stillage management, managers, decision makers, consultants, policy makers, regulators and researchers demonstrated concerns on their own side. However, almost all need decision input that bases on the facts obtained through scientific investigation. Due to the cost and technocomplex implication of another alternatives to manage stillage, the anaerobic digestion (AD) of stillage remains robust, simple and feasible technique ${ }^{15-17}$

In an effort to curb the water, energy and environment issues in stillage management, several studies have attempted to treat stillage using various techniques. In spite of the fact that detoxification and energy gain from stillage is a big deal, researches have applied synthetic wastewater to simulate stillage, 
whose product may not be generalizable in real scenario ${ }^{18}$. Those tests on real ethanol wastewater remained at an efficiency of around 80\% COD removal ${ }^{19-21}$ whereby most of the studies were even performed under batch $A D{ }^{12,22}$. Few studies have been tested on continuous mode and the improved performance of $A D$ was reported under fixed film digestion ${ }^{19}$. The fixed film $A D$ used some media to pack the digesters with some synthetic medium which would help attach biofilm ${ }^{10,23,24}$.

Though there are emerging $A D$ techniques for an improved stillage COD reduction ${ }^{25}$, still they are applied at a reduced COD feed concentration. Consequently, most investigations end up concluding on the importance of integrated stillage treatment, which include feed pretreatment, $A D$ and aerobic degradation 26-28. Therefore, the objective of the current study is to evaluate the effect of stillage pretreatment on the Organic Loading Rate (OLR) and the subsequent COD removal under continuous AD process. It further examined the effect of scoria, and natural vesicular rock on AD system.

\section{Materials And Methods}

\subsection{Experimental setting}

In the current study, the experiments were run in sequence as depicted in Fig. 1. The stillage brought from the molasses ethanol factory was first characterized. Following that, subsample of the stillage was mildly wet air pretreated in a four necked glass vessel using air at a flow rate of 2 liters/minute and temperature of $60^{\circ} \mathrm{C}$. The mild and iron oxide coated sand based ( $3.5 \%$ by weight) wet air pretreatment was conducted for a period of four hours. After wet air oxidation(WAO) of the stillage, the sample was moved onto a continuous $A D$ alongside of the raw subsample of stillage. Later, a predetermined soluble $C O D$ containing $\left(C O D_{\text {sol }}\right)$ reject water from the $A D$ was moved to the aerobic degradation bottle of one-liter volume glass reactor. The reactor was sparged with air supplied from an external electric pump. Both the $A D$ and aerobic degradation were performed at mesophilic temperatures $\left(35 \pm 2{ }^{\circ} \mathrm{C}\right)$ (Fig. 1).

The experiments on biogas yield and COD removal has been conducted on a semi-continuous upflowed anaerobic digester. The aim of the semi-continuous system experiment was to evaluate the performance of the COD removal from the stillage feed. Anaerobic digesters of two liters working volumes were constructed in the lab using acrylic sheets, plastic funnels, silicon tubing, clamps, pumps, and a multipurpose sealant among other materials. The digesters construction includes those accessories assembled, including the feed tank, electric pumps fixed around 150 revolutions per minute, feed inlet, gas exit and effluent ports on which the silicon tubes are fitted, and the beakers to collect the exiting effluent as well as the upright table to fix the digesters erected. Both digesters were packed with coarse scoria, a vesicular mineral rock produced in volcanos. The anaerobically treated stillage was further moved to polishing aerobic degradation. The aerobic polishing was performed using one-liter volume batch glass reactors connected to electric pump and sampling ports (Fig. 1).

\subsection{Sampling}




\subsubsection{Scoria sampling}

Scoria, which is a volcanic rock prevailing in the rift valley region of Ethiopia has been brought from two locations whose coordinates are taken as indicated in figure one (Fig. 2). The scoria has been broken down to a relatively uniform coarse size and was washed with tap water before packing.

Characteristically, the raw scoria has been examined for its morphology and elemental composition using x-ray diffraction (XRD), scanning electron microscopy (SEM) and SEMEDEX. The SEMEDEX analysis of the scoria was performed in SwiftED3000 to quantify all elements whose analysis took an acquisition time of 60 seconds, a process time of four minutes and an accelerating voltage of $15 \mathrm{kV}$. No coating was applied. By composition the top four elements are oxygen (70\%), silicon (15\%), aluminum (5\%) and iron (3\%). (Fig. 3).

The XRD image read at 2 thetas showed the non-amorphous nature of the rock. The SEM image of the raw scoria showed a rough surface nature, which may help biofilms attach over a wide surface area in the anaerobic digesters. A further analysis of the scoria using the Fourier Transform Infrared Spectroscopy (FTIR) is presented (Fig. 4).

\subsubsection{Stillage sampling}

A real molasses ethanol stillage sample was brought from Aligarh, Uttar Pradesh State, India. The sample has been car transported in plastic container within four hours to the working laboratory where it was further subsampled, analyzed and got cold stored.

\subsection{Inocula}

Composites of inocula were grabbed from different places. One was from a lab stock of the AD crew maintained viable by feeding glucose solution periodically (Table 1 ), the other was brought from a sewage AD process operating at a place in Delhi, India. 
Table 1

Formulation ingredients of glucose solution for inocula activation

\begin{tabular}{|ll|}
\hline Constituent & Composition, (g/L) \\
\hline Glucose (dextrose) & 10 \\
\hline Yeast extract & 0.34 \\
\hline Ammonium chloride & 0.84 \\
\hline Potassium dihydrogen phosphate & 0.136 \\
\hline Dipotassium hydrogen phosphate & 0.23 \\
Magnesium chloride & 0.084 \\
\hline Ferric chloride & 0.05 \\
\hline Calcium chloride & 0.09 \\
\hline Distilled water & Rest \\
\hline
\end{tabular}

\subsection{Analysis and equipment}

Standard methods were followed in the determination of stillage parameters, which include BOD and COD, before and after treatment, mainly performed based on the American Public Health Association outline ${ }^{29}$. However, other standard procedures were also referred from related peer reviewed journals 30,31 . During analysis, prior calibration of instruments, which include the $\mathrm{pH}$ meter and the spectrophotometer (JENWAY 7305) have also been performed.

A thermal Conductivity Detector (TCD) based gas chromatography (GC) was used for the analysis of biogas methane (5700 NUCON). The GC carrier gas used was hydrogen performed at a detection temperature of around $90^{\circ} \mathrm{C}$. The oven temperature or the $\mathrm{GC}$-injector temperature was always kept around $80^{\circ} \mathrm{C}$. Additionally, weighing (Sartorius, Thermo Scientific $\left.{ }^{\circledR}\right), \mathrm{pH}$ measuring (CyberScan pH 510, Thermo Scientific), centrifuging equipment (MiniSpin ML079, EPPENDORF®/ Centrifuge 5804 R, EPPENDORF® / SORVALL, LYNX6000 Centrifuge Thermo Scientific $®)$ and advanced analytic instrument were used (INSPECTFS and SwiftED3000). The FTIR was performed using instrument FTIR Nicolet iS05.

\subsection{Data analysis}

Collected meticulous data was first entered in excel and later statistical analyses were performed in R, version 3.6.3. 2020-02-29. The results obtained were also discussed by contrasting them with existing evidence.

\section{Results And Discussion}


Initially the molasses stillage sample was characterized for its composition. The COD of the sample was so high, which was measured to be above $2,32,000 \mathrm{mg} / \mathrm{L}$ with a BOD of $133,000 \mathrm{mg} / \mathrm{L}$. However, the AD was started at a lower OLR of $120 \mathrm{mg} / \mathrm{L} \mathrm{COD}_{\text {sol }}$ by diluting the original sample.

\subsubsection{The startup periods}

After digester setup was completed, a lab preserved inoculum of $1.5 \mathrm{~L}$ was added to each of the already $40 \%$ scoria packed anaerobic digesters. Afterwards, the viability of the system was monitored using $\mathrm{pH}$ and methane production for three days, which was followed by feeding a glucose solution formulated in the lab as presented in table one under the method section.

Among other issues, process stability in $A D$ behaves as a function of substrate type, system susceptibility to xenobiotics, the mode of operation and temperature, either continuous or batch or thermophilic or mesophilic, and $\mathrm{pH}^{32}$. Thus, towards reaching stable operation, glucose solution and glucose stillage mix have been fed to digesters. However, $\mathrm{pH}$ drops of scale over 1.5 have been recorded in just four days during the second week that also followed poor methane generation with lower percentages (10\% methane). Consequently, a mix of anaerobic sludge from a working waste activated sludge AD was obtained and supplemented to the current experiment. Generally, stability in $\mathrm{pH}$ has been monitored for over 40 days and the results are show in Fig. 5.

The slightly lower $\mathrm{pH}$ on the second day of the pseudo-steady operation of the reactor ' $\mathrm{A}$ ' was associated with the relatively higher initial COD and the subsequent hydrolysis and acidogenesis activities happening in the system. Though the slight variation in $\mathrm{pH}$ between the two systems persisted nearly all the time, the $\mathrm{pH}$ of both systems was maintained between 6 and 8 during the entire start up period. Maximums of 8.0 and 7.7 and minimums of 6.7 and $6.1 \mathrm{pH}$ have been recorded for the digester ' $A$ ' and ' $\mathrm{B}$ ' subsequently. However, the $\mathrm{pH}$ monitored showed a significant difference between reactors ' $A$ ' and ' $B$ ' ( $\mathrm{p}$ value $=0.00$ ) based on a t-test performed in $\mathrm{R}$. Despite their major disparity in $\mathrm{pH}$, the two digesters were within desirable ranges of $\mathrm{pH}$ except the slight increase recorded by digester ' $A$ '. After the establishment of a relative stability in $\mathrm{pH}$, the test runs were started aiming at the COD removal efficiency of both digesters fed simultaneously and the OLR as well as feed were changed over time.

\subsubsection{COD removal efficiency variation with feed pretreatment}

Average values from both digesters were taken for nearly two months after establishing pseudo-steady state conditions whereby OLR was varied between 2 to 3 weeks. The entire runs were repeated except changing the feed type from the raw molasses ethanol stillage to a WAO pretreated one. The COD after the stabilized $\mathrm{pH}$ was showing negative removal for the first two days, which could be due to leaching from the packing material, release of extracellular polymeric substances in the sludge inoculum, poor mixing in the system as well as the use of undiluted samples for the COD analysis. Despite the accumulating COD, the $\mathrm{pH}$ of both reactors was on a slight increase that would be due to the effect of the packing material. 
After giving some time to run both systems, the two reactors were compared against feed type for COD removal efficiency with respect to the OLR applied. Upon establishing a steady operating conditions, the OLR and the COD removal efficiency in percentage is compared between the $\mathrm{WAO}_{p}$ and the raw feed. The averaged organic/stillage loading rate against the $\mathrm{COD}_{\text {sol }}$ removed has been compared between the wet air pretreated $\left(\operatorname{CODr}(\mathrm{mg} / \mathrm{L}) \_\right.$WAO) and the unpretreated $\left(\mathrm{COD}_{\mathrm{r}}(\mathrm{mg} / \mathrm{L})\right)$ for which the graph shows a relatively better performance of the earlier. Furthermore, the two systems showed inverse relation in COD removal against loading from $1667 \mathrm{mg} / \mathrm{L}-\mathrm{d}$ upwards. Further, based on a simple linear regression modelling of the COD removal a visible difference between the WAOp feed and the raw feed has been observed; which is $C O D r=0.022 x \mathrm{OLR}+2.7381$ and $\mathrm{CODr}=0.0167 \times \mathrm{xOR}+0.6264$ respectively. Indeed, the difference in the regression constants as well as the regression coefficients was tested for statistical significance. Based on Wilcoxon signed rank test with continuity correction, both variables have proved to be different ( $p$-value $=0.036$ ) with an average of $13 \%$ difference in COD removal.

Despite the decline on the average COD removal at $1667 \mathrm{mg} / \mathrm{L} \mathrm{OLR}$, the $W A O_{p}$ feed showed increased removal. The improved removal continued even on the highest OLR of $2000 \mathrm{mg} / \mathrm{L}$ that signals the opportunity to higher loading possibility of such pretreated feeds in AD while maintaining better efficiency in the COD reduction. On the contrary, the unpretreated fed showed steep decline in COD removal with such an increase in OLR (Fig. 6). In fact, physicochemical pretreatments are reported to recover more methane thereby removing more COD in $A D$ at various loading rates. ${ }^{33,34}$ Though the data obtained in this study is for comparison purpose, the issues with continuous operation of the systems, air interference and hence poor mixing contributed to the overall low performance of both systems.

Though the focus of the current study was to see the effect of the stillage pretreatment on the removal of the COD in AD with respect to varied OLR, the methane content of both systems was also followed periodically. As a result, a negligible variation in percentage methane content was obtained between the digesters and among OLR, ranging between $37 \%$ and $40 \%$ on average. However, a relatively better percent methane (up to $42 \%$ ) was frequently recorded by the digester which was fed with a $\mathrm{WAO}_{\mathrm{p}}$ stillage. In a related experiment, the reject water from the $A D$ testing was moved to a polishing treatment, the aerobic degradation.

\subsection{Aerobic batch digestion of the post anaerobic digested pretreated stillage}

Though there is a relatively recent attraction in $A D$, aerobic degradation is used to be the main systems in wastewater treatment since earlier times. The oxygen molecule being the terminal electron acceptor, the degradation of organic molecule results in the transformation of organic molecules to cell masses and mineral byproducts, including the endogenous respiration. In such schemes, the rate of oxygen consumption is stoichiometrically linked the organic utilization rate to cell mass buildup in the system ${ }^{35}$. 
Aerobic systems are good for their shorter hydraulic retention time. Though, the process demands many variables with a higher biomass yield resulting in a huge mass of sludge.

The mechanical supply of air/oxygen, nutrient system supplement as well as diversification of the consortia of organisms as degrading crew among other environmental factors is used to be a process performance determinant. However, aeration cost and the resulting biomass buildup that gives up secondary waste are among the influencing parameters to prefer anaerobic systems to it. On the other hand, the application of either of the two systems alone is less efficient, especially in the treatment of complex industrial waste including distillery stillage ${ }^{32}$. Therefore, the coupled application of both systems is reported to have a desirable effect on the degradation of stillage including the application of different pretreatments. The aerobic degradation potential of the stillage after the $W_{A} O_{p} A D$ is performed in the current study to see if the final removal is desirable to meet discharge limits, which is becoming widely and increasingly stringent.

With the perspective that the coupling of aerobic and anaerobic digestion of organic matter increases the removal efficiency ${ }^{36}$, the anaerobically treated stillage is moved to aerobic digesters. Aerobic reactors, glass bottles of one-liter volume were constructed to run the experiment. Rubber corks, plastic tubes and air blowers were used to mechanically supply air, insert the feed and remove samples as well as for monitoring the systems, which were running in duplicates for over eight days. During those experimental days, the COD removal of the feed, including the glucose concentration supplement, was monitored along with $\mathrm{pH}$ and DO (Fig. 7).

Even though there were drops in DO up to $2-3 \mathrm{mg} / \mathrm{L}$ in the systems during the initial and when glucose supplement was performed, mostly read DO was around $6 \mathrm{mg} / \mathrm{L}$. Though the optimal $\mathrm{pH}$ was around 7 and a pH of 6-9 is tolerable ${ }^{35}$, there were times when the $\mathrm{pH}$ of the systems went over 9 , especially during the first three days of the experiment. Consequently, regulating the rise in $\mathrm{pH}$ was done by adding more inoculum on the third day and by using a $2 \% \mathrm{HCl}$ solution, which was added to a volume of $5-$ $10 \mathrm{~mL}$ to each reactor.

Unfortunately, the nonbiodegradable COD remained resistant even after the aerobic degradation period was over. The best COD removal (68\%) in the process was attained in just eight hours. In fact, the final corrected COD after aerobic degradation is still around $2278 \mathrm{mg} / \mathrm{L}$; however, it is far better when compared to the removal of the same, which was obtained from prior studies and of course that is far better than the same COD measured after the AD was completed ${ }^{28}$. During the aerobic test, the least COD measured is attained within four days. Besides, it has to be noted from the graph that the negative removals were representing the effect of the glucose solution added on the fifth day and it has been understood that its addition had no effect on enhancing the COD removal despite the expectation that it could have done otherwise (Fig. 7).

The aerobic degradation has improved the overall average COD removal efficiency of the integrated treatment in the current study. Thus, the elimination efficiency has brought above $90 \%$, which is very 
much closer to the set distillery wastewater (DWW) discharge limit set by the authorities, by considering the concentrated stillage alone without mixing another component wastewater in the sector. More importantly, the current integrated biological treatment has completely removed the BOD of the stillage feed. In Ethiopia, the discharge limits are set to be able to join the natural water streams, which is established at $250 \mathrm{mg}-\mathrm{COD} / \mathrm{L}$ and $60 \mathrm{mg}-\mathrm{BOD} / \mathrm{L}$ effluent or less for the ethanol industries.

Despite the existing reality of the local river pollution, which is already becoming open channels of wastewater of either industrial, municipal or agricultural origin because of the absence of well laid infrastructure for sewage management, industrial discharge limits can have alternatives. For instance, the discharge limits can be set at two levels: one for connecting to the local municipal sewage system and the other for joining water bodies or just the natural environment including the land, the former being at a relatively high level. In such cases, discharge limits are set at two stages whereby linking to sewage can easily be met.

Considering the huge water portion in the entire DWW, this degree of reduced COD level along with total BOD removal can meet the discharge limits on its own even without the need to join other municipal waste streams as far as COD and BOD are concerned. Moreover, it is not only pollution minimization but the recovery of water also has to be given large emphasis as the sector is part of a major water consuming category, that is the industry and agriculture, that consume $90 \%$ of the overall global freshwater ${ }^{37}$. Such removal efficiency is superior compared to reports based on coupled treatment studies ${ }^{19,38,39}$.

\section{Conclusions And Recommendations}

The COD removal by the continuous $A D$ of stillage alone is not sufficient either to meet discharge limits or to efficiently recover the renewable energy potential contained in molasses stillage. The percent average COD removal in the AD of a WAOp stillage was always better than the raw counterpart, which suggests that pretreatment of the cane molasses distillery stillage can improve the removal of the COD thereby enhancing the energy recovery under optimum OLR. The application of scoria packing could help absorb substrate shock in the AD systems, thus it may stabilize the $\mathrm{pH}$. Shorter holding time, which is around eight hours, in the units for aerobic degradation of stillage would be enough to remove a significant portion of the COD. However, regulation of the $\mathrm{pH}$ to an optimum level is a challenge in aerobic systems. Existing ethanol distillery industries have to adapt to locally available, robust and sustainable techniques to recover their residue, which is produced massively, and thereby protect the natural ecosystem.

\section{Abbreviations}

$A D$ - anaerobic digestion

COD - chemical oxygen demand

COD/BOD - chemical/biological oxygen demand 
OLR - Organic Loading Rate

WAO - wet air oxidation

$\mathrm{COD}_{\text {sol }}$ - soluble COD containing

XRD - x-ray diffraction

SEM- scanning electron microscopy

FTIR - Fourier Transform Infrared Spectroscopy

TCD - Thermal Conductivity Detector

GC - Gas chromatography

DWW - distillery wastewater

\section{Declarations}

\section{Ethics approval and consent to participate}

All the authors have read and agreed the ethics for publishing the manuscript.

\section{Consent for publication}

The authors approved the consent for publishing the manuscript.

\section{Availability of data and materials}

The authors approved the availability of data and materials for publishing the manuscript..

\section{Competing interests}

The authors declare that they have no conflict of interest.

\section{Funding}

This research did not receive any specific grant from funding agencies in the public, commercial, or notfor-profit sectors. 


\section{Authors' contributions}

Getachew D. Gebreeyessus -Investigation; Data curation; Resources; Writing - original draft, Andualem Mekonnen:, Yonas Chebude- Investigation; Data curation; Formal analysis; Resources, Perumal Asaithambi-Conceptualization; Methodology; Validation; Supervision., Esayas Alemayehu Conceptualization; Methodology; Validation; Supervision.

\section{Acknowledgements}

This work would not have been realized without the involvement of the vibrant lab team working in the Wastewater Treatment Lab of the Indian Institute of Technology, Delhi. Therefore, we are so grateful to those team members working there. Our special thank goes to Dr. Ashish Kumar Lohar whose unreserved collaboration remains to be a good lesson.

\section{References}

1. Im PK, Millwood IY, Guo Y, et al. Patterns and trends of alcohol consumption in rural and urban areas of China: findings from the China Kadoorie Biobank. BMC Public Health. 2019/02/20 2019;19(1):217.

2. Little W, McGivern R, Kerins N. Introduction to Sociology-2nd Canadian Edition. BC Campus; 2016.

3. Aliyu AA, Amadu L. Urbanization, cities, and health: The challenges to Nigeria - A review. Ann Afr Med. Oct-Dec 2017;16(4):149-158.

4. Satterthwaite D, McGranahan G, Tacoli C. Urbanization and its implications for food and farming. Philos Trans R Soc Lond B Biol Sci. 2010;365(1554):2809-2820.

5. Rehm J, Kilian C, Ferreira-Borges C, et al. Alcohol use in times of the COVID 19: Implications for monitoring and policy. Drug and Alcohol Review. 2020.

6. Zhang C, Chen X, Li Y, Ding W, Fu G. Water-energy-food nexus: Concepts, questions and methodologies. Journal of Cleaner Production. 2018;195:625-639.

7. Sheehan J, Aden A, Paustian K, et al. Energy and environmental aspects of using corn stover for fuel ethanol. Journal of Industrial Ecology. 2003;7(3-4):117-146.

8. Lazarova V, Choo K-H, Cornel P. Water-energy interactions in water reuse. IWA publishing; 2012.

9. Smeets E, Junginger H, Faaij A, Walter A, Dolzan P. Sustainability of Brazilian bio-ethanol. Vol 2006: UU CHEM NW\&S (Copernicus); 2006.

10. Gebreeyessus GD, Mekonnen A, Alemayehu E. A review on progresses and performances in distillery stillage management. Journal of Cleaner Production. 2019;232:295-307.

11. de Oliveira Bordonal R, Carvalho JLN, Lal R, de Figueiredo EB, de Oliveira BG, La Scala N. Sustainability of sugarcane production in Brazil. A review. Agronomy for Sustainable Development. 2018;38(2):13. 
12. Wilkie AC, Riedesel KJ, Owens JM. Stillage characterization and anaerobic treatment of ethanol stillage from conventional and cellulosic feedstocks. Biomass and Bioenergy. 2000;19(2):63-102.

13. Noukeu N, Gouado I, Priso R, et al. Characterization of effluent from food processing industries and stillage treatment trial with Eichhornia crassipes (Mart.) and Panicum maximum (Jacq.). Water resources and industry. 2016;16:1-18.

14. Beltrán FJ, Álvarez PM, Rodríguez EM, García-Araya JF, Rivas J. Treatment of high strength distillery wastewater (cherry stillage) by integrated aerobic biological oxidation and ozonation. Biotechnology progress. 2001;17(3):462-467.

15. Longati AA, Lino AR, Giordano RC, Furlan FF, Cruz AJ. Biogas production from anaerobic digestion of vinasse in sugarcane biorefinery: a techno-economic and environmental analysis. Waste and Biomass Valorization. 2019:1-19.

16. Chanthawong A, Dhakal S. Stakeholders' perceptions on challenges and opportunities for biodiesel and bioethanol policy development in Thailand. Energy Policy. 2016;91:189-206.

17. Anderson P, Baumberg B. Stakeholders' views of alcohol policy. Nordic Studies on Alcohol and Drugs. 2006;23(6):393-414.

18. Pradeep NV, Anupama S, Navya K, Shalini HN, Idris M, Hampannavar US. Biological removal of phenol from wastewaters: a mini review. Applied Water Science. 2015/06/01 2015;5(2):105-112.

19. Kharayat Y. Distillery wastewater: bioremediation approaches. Journal of Integrative Environmental Sciences. 2012/06/01 2012;9(2):69-91.

20. Luo G, Xie L, Zhou Q. Enhanced treatment efficiency of an anaerobic sequencing batch reactor (ASBR) for cassava stillage with high solids content. Journal of bioscience and bioengineering. 2009/06// 2009;107(6):641-645.

21. Espana-Gamboa E, Mijangos-Cortes J, Barahona-Perez L, Dominguez-Maldonado J, HernándezZarate G, Alzate-Gaviria L. Vinasses: characterization and treatments. Waste management \& research. 2011;29(12):1235-1250.

22. Beltrán FJ, Álvarez PM, Rodríguez EM, García-Araya JF, Rivas J. Treatment of High Strength Distillery Wastewater (Cherry Stillage) by Integrated Aerobic Biological Oxidation and Ozonation. Biotechnology progress. 2001;17(3):462-467.

23. Eskicioglu C, Kennedy KJ, Marin J, Strehler B. Anaerobic digestion of whole stillage from dry-grind corn ethanol plant under mesophilic and thermophilic conditions. Bioresource technology. 2011;102(2):1079-1086.

24. Eskicioglu C, Ghorbani M. Effect of inoculum/substrate ratio on mesophilic anaerobic digestion of bioethanol plant whole stillage in batch mode. Process Biochemistry. 2011;46(8):1682-1687.

25. Sayedin F, Kermanshahi-pour A, He QS. Evaluating the potential of a novel anaerobic baffled reactor for anaerobic digestion of thin stillage: Effect of organic loading rate, hydraulic retention time and recycle ratio. Renewable Energy. 2019;135:975-983.

26. Apollo S, Onyango MS, Ochieng A. An integrated anaerobic digestion and UV photocatalytic treatment of distillery wastewater. Journal of hazardous materials. 2013;261:435-442. 
27. Padi RK, Chimphango A. Feasibility of commercial waste biorefineries for cassava starch industries: Techno-economic assessment. Bioresource Technology. 2020;297:122461.

28. Mikucka W, Zielińska M. Distillery Stillage: Characteristics, Treatment, and Valorization. Applied Biochemistry and Biotechnology. 2020/06/18 2020.

29. APHA; WWA \& WEF APHAWWAaWEF. Standard methods for the examination of water and wastewater. Solids. USA: Amer Public Health Assn; 1999:7.

30. Jardim WF, Pasquini C, Guimarães JR, de Faria LC. Short-term toxicity test using Escherichia coli: Monitoring CO2 production by flow injection analysis. Water research. 1990/03/01/ 1990;24(3):351354.

31. Robbens J, Dardenne F, Devriese L, De Coen W, Blust R. Escherichia coli as a bioreporter in ecotoxicology. Applied microbiology and biotechnology. Nov 2010;88(5):1007-1025.

32. Gebreeyessus GD, Jenicek P. Thermophilic versus mesophilic anaerobic digestion of sewage sludge: a comparative review. Bioengineering. 2016;3(2):15.

33. Ma C, Liu J, Ye M, Zou L, Qian G, Li Y-Y. Towards utmost bioenergy conversion efficiency of food waste: Pretreatment, co-digestion, and reactor type. Renewable and Sustainable Energy Reviews. 2018/07/01/ 2018;90:700-709.

34. Zhang H, Wang L, Dai Z, Zhang R, Chen C, Liu G. Effect of organic loading, feed-to-inoculum ratio, and pretreatment on the anaerobic digestion of tobacco stalks. Bioresource Technology. 2020/02/01/ 2020;298:122474.

35. Eddy M. Watewater engineering treatment and reuse. In: George Tchobanglous FLB, H. David Stensel, ed. Fourth ed. Tiwan: McGraw-Hill Companies, Inc.; 2003.

36. Novak JT, Banjade S, Murthy SN. Combined anaerobic and aerobic digestion for increased solids reduction and nitrogen removal. Water research. 2011/01/01/ 2011;45(2):618-624.

37. Supply WUJW, Programme SM, Organization WH. Progress on sanitation and drinking water: 2015 update and MDG assessment. World Health Organization; 2015.

38. Beltran FJ, Alvarez PM, Rodriguez EM, Garcia-Araya JF, Rivas J. Treatment of high strength distillery wastewater (cherry stillage) by integrated aerobic biological oxidation and ozonation. Biotechnology progress. May-Jun 2001;17(3):462-467.

39. Beltrán FJ, Álvarez PM, Rodríguez EM, García-Araya JF, Rivas J. Treatment of High Strength Distillery Wastewater (Cherry Stillage) by Integrated Aerobic Biological Oxidation and Ozonation.

Biotechnology progress. 2001/01/01 2008;17(3):462-467.

\section{Figures}




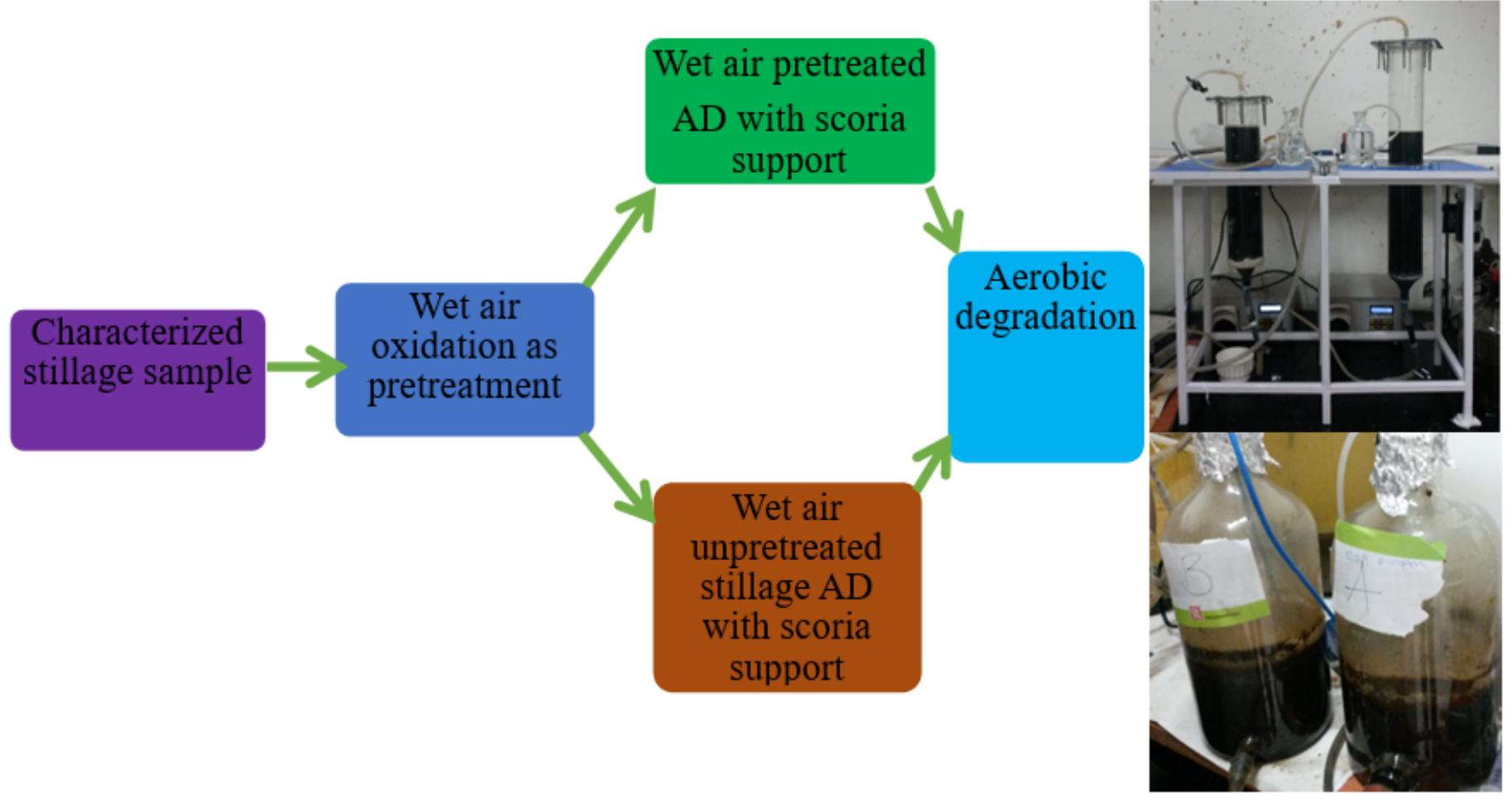

Figure 1

The diagrammatic and photographic setup of the experiments.
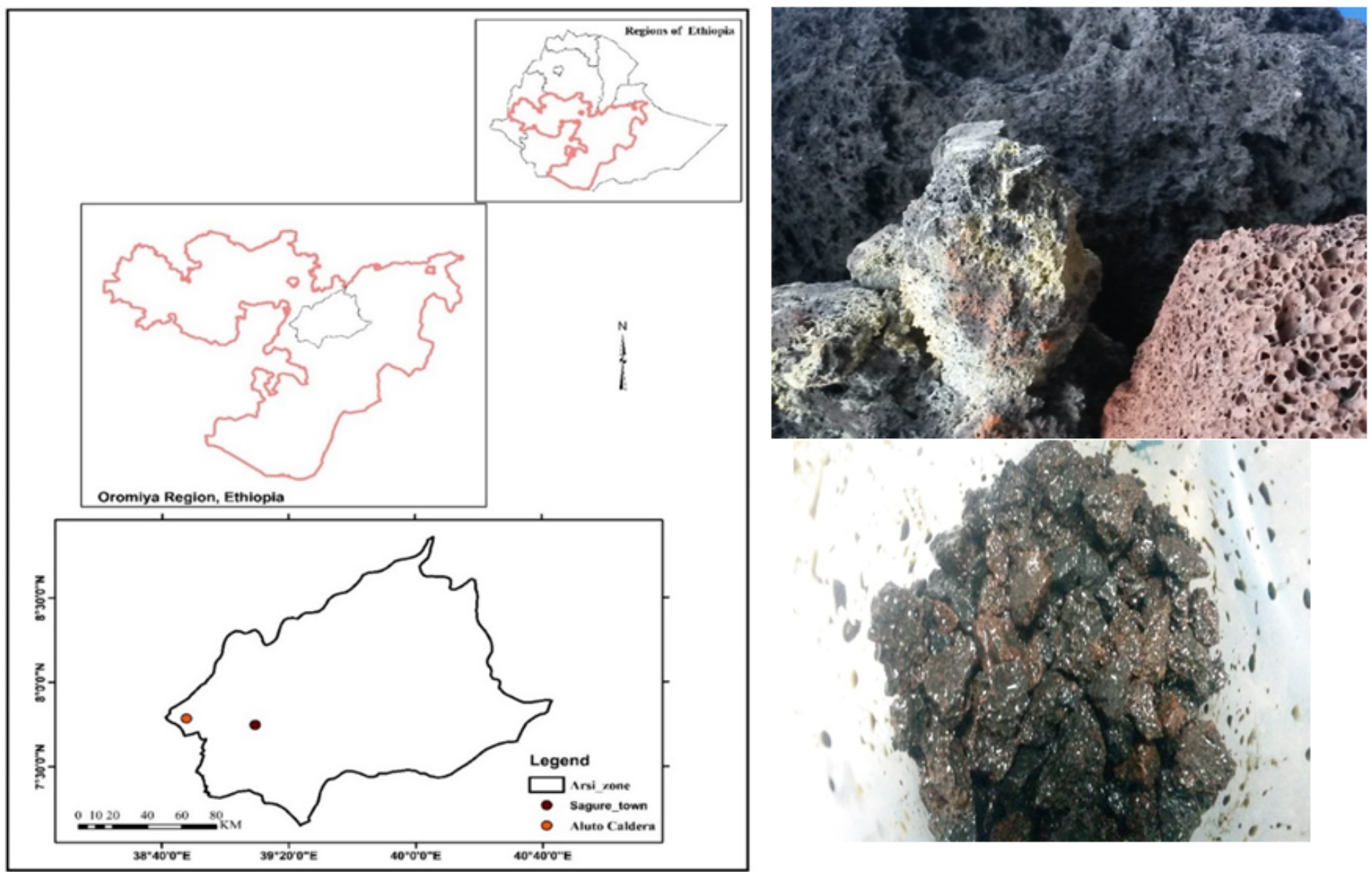
Figure 2

The location points (left), raw (top-right) and used (bottom- right) images of scoria sample used for the anaerobic digester packing.

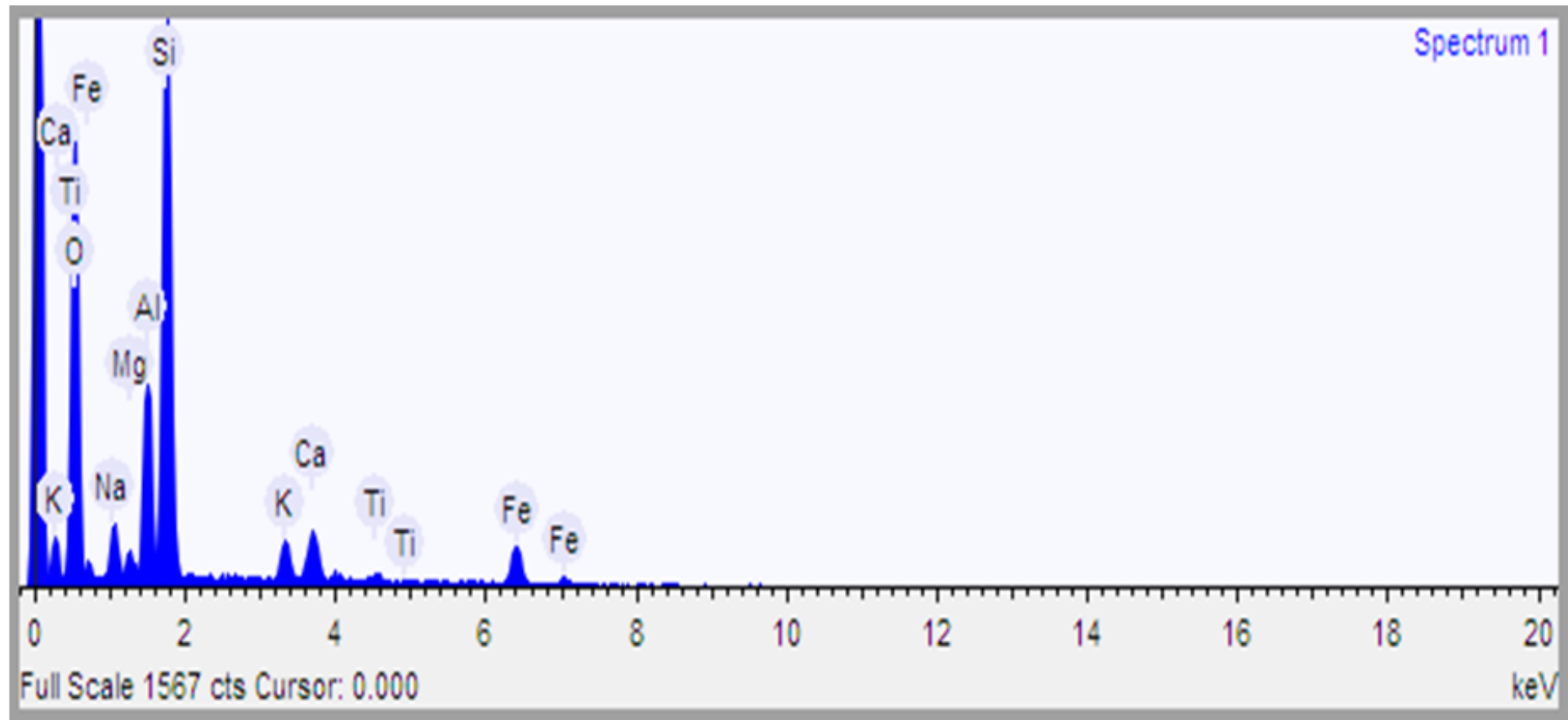

Figure 3

Spectrum of elemental composition of the raw scoria. 


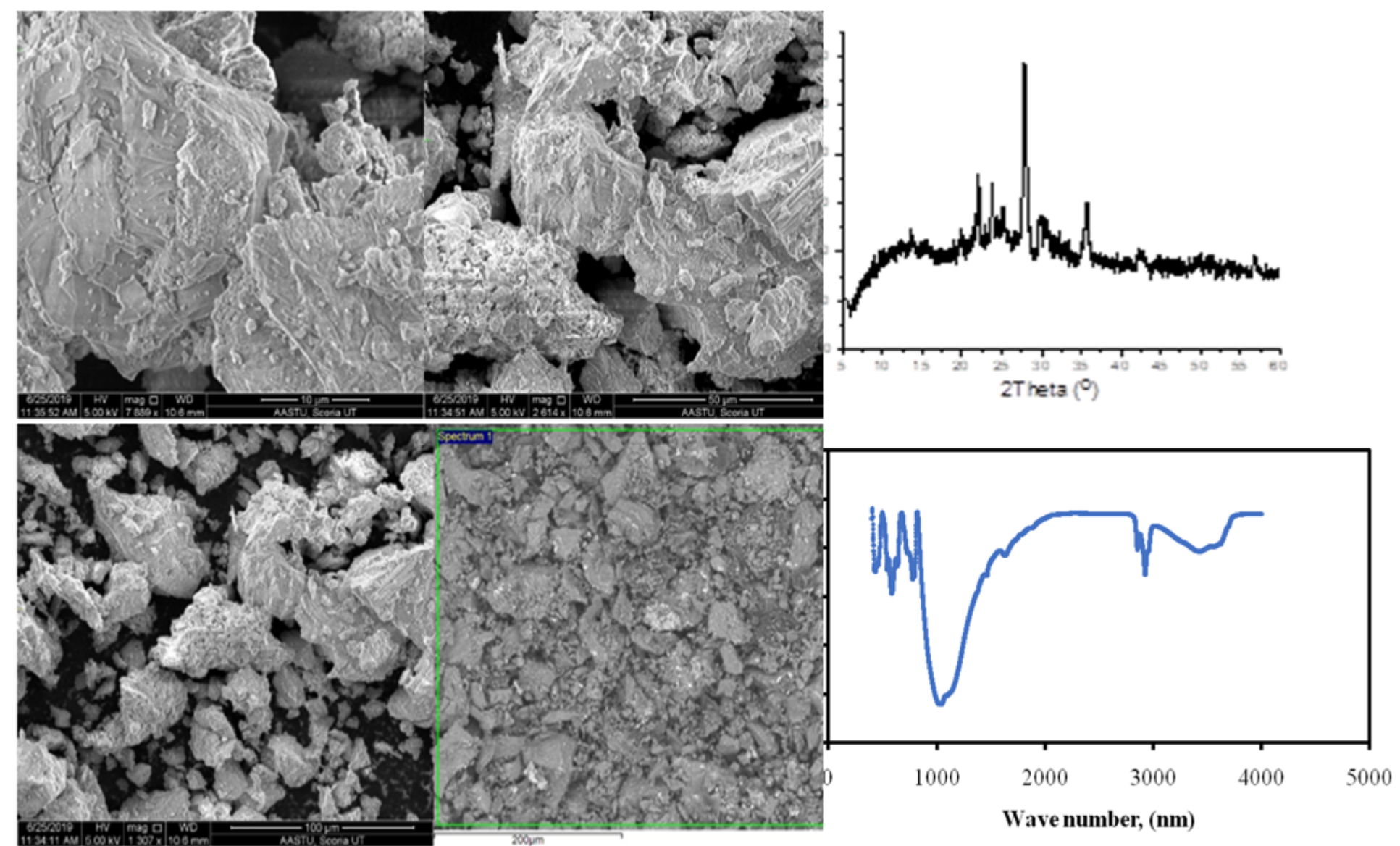

\section{Figure 4}

X-ray diffraction (right top) and scanning electron microscopic images taken at 10, 50, 100 and $474.1 \mu \mathrm{m}$ resolutions (left) as well as the Fourier Transform Spectroscopy (right bottom) for the raw scoria.

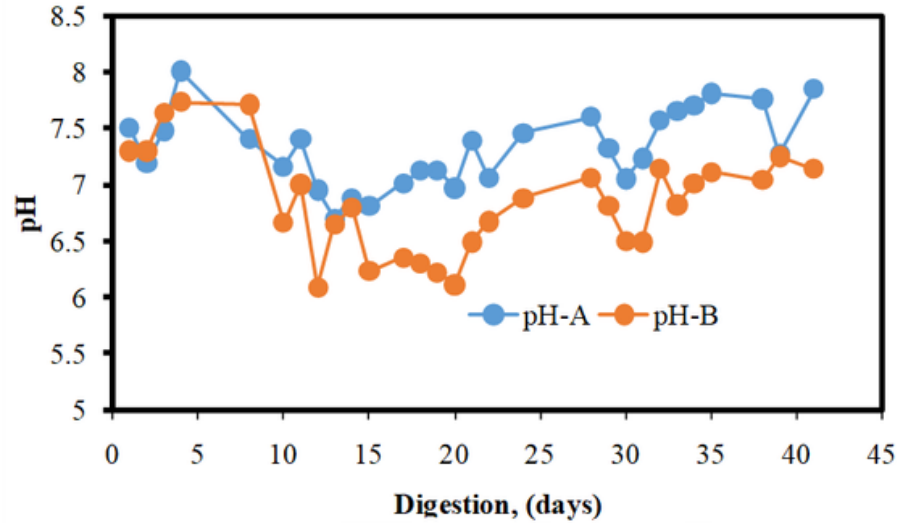

(a)

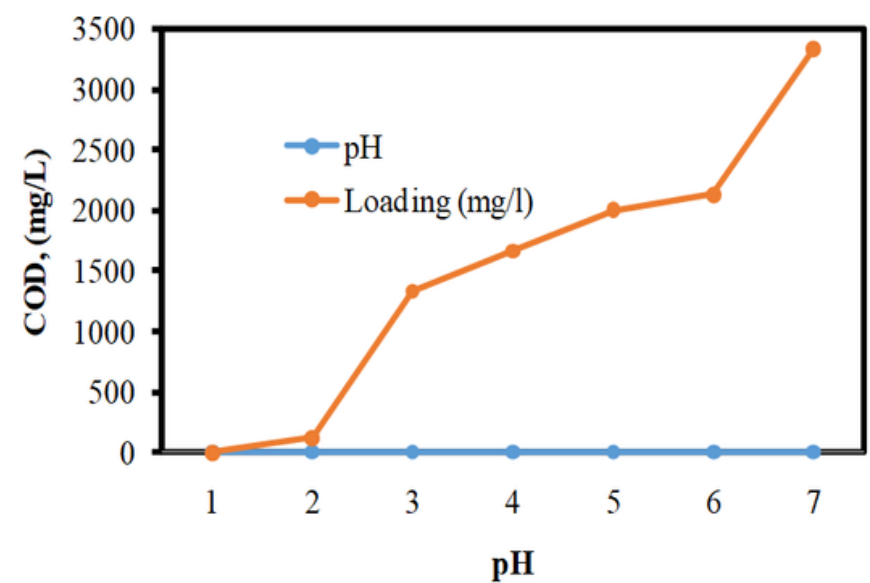

(b)

\section{Figure 5}

Results of $\mathrm{pH}$ monitoring (left) and $\mathrm{pH}$ versus loading rate (right) in the continuous anaerobic digesters over time. 


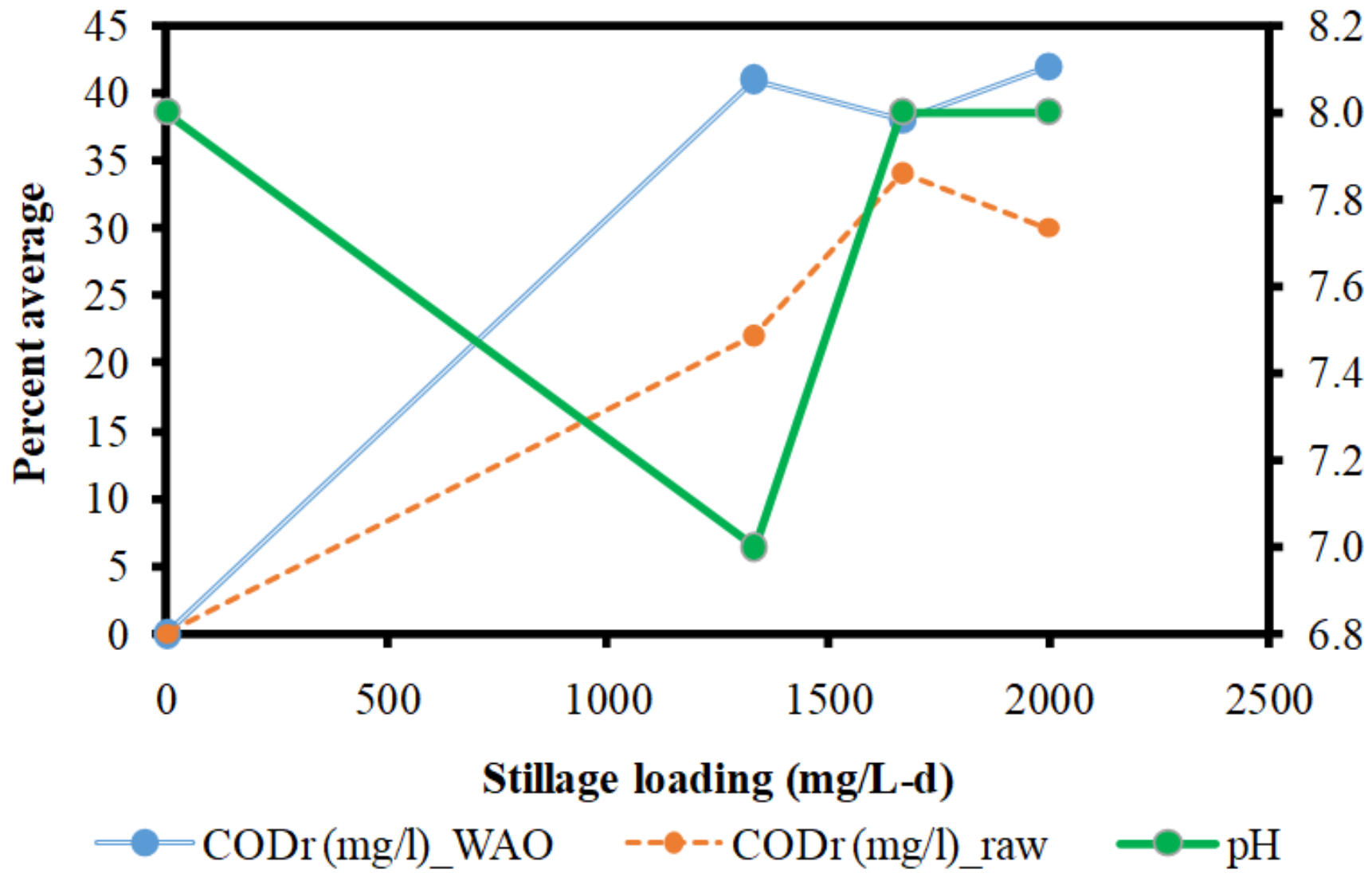

Figure 6

Stillage anaerobic digestion average $\mathrm{pH}$ and COD removal difference between wet air pretreated (CODr (mg/L)_WAO) versus the raw feed (CODr (mg/L)_raw). 


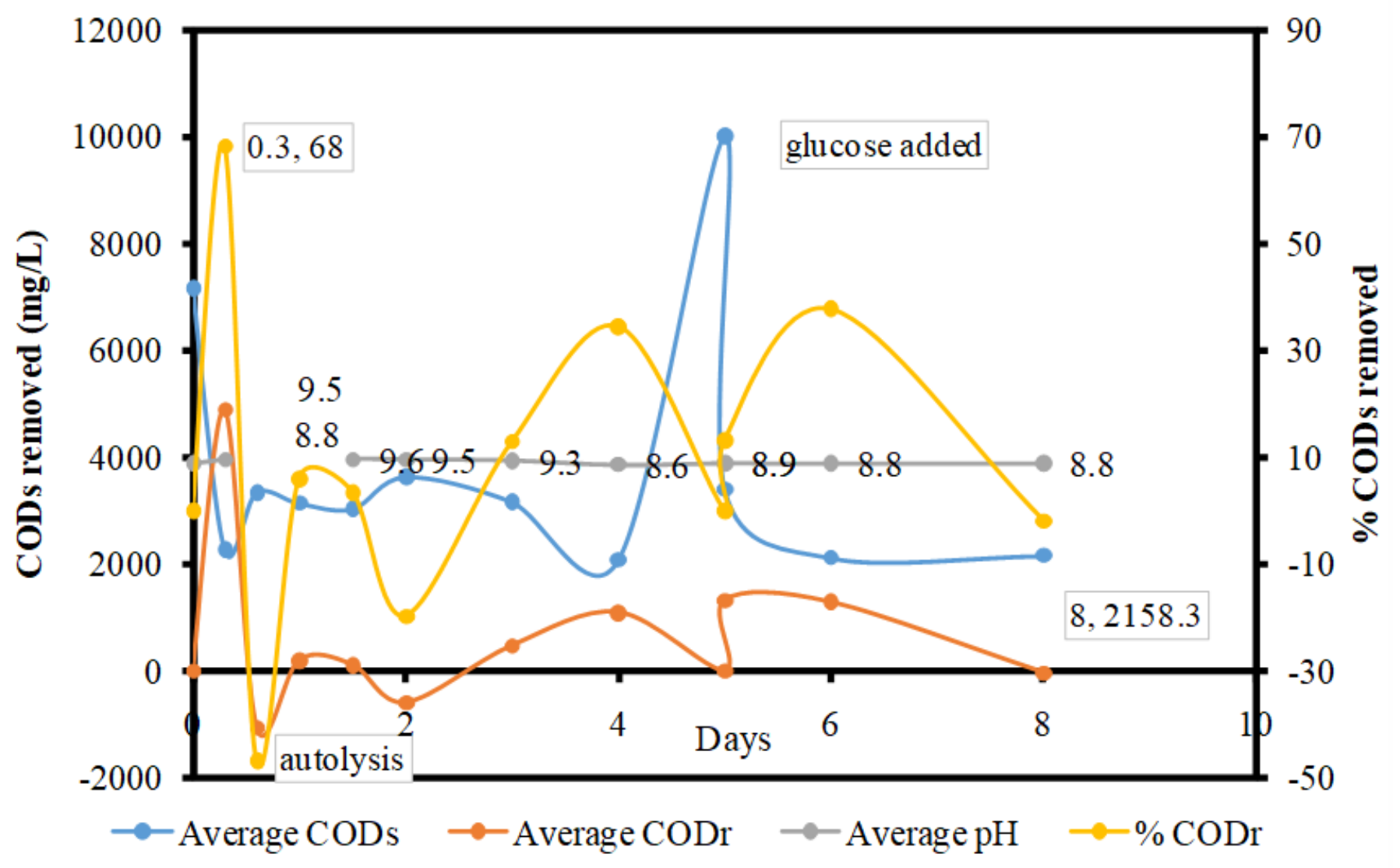

Figure 7

Monitoring the result of soluble chemical oxygen demand removal and $\mathrm{pH}$ in the aerobic degradation of the wet air pretreated and biomethanated molasses distillery stillage

\section{Supplementary Files}

This is a list of supplementary files associated with this preprint. Click to download.

- Graphicalabstract.docx 